\title{
Left ventricular to right atrial shunt resulting from infective endocarditis
}

\author{
C. J. ELLIS ${ }^{1}, K$. E. GRAY, and D.A.P. A I N S C O ${ }^{2}$ \\ The Cardiac Department, Bristol General Hospital, Guinea Street, Bristol BS1 $6 S Y$
}

\begin{abstract}
Ellis, C. J., Gray, K. E., and Ainscow, D. A. P. (1975). Thorax, 30, 118-120. Left ventricular to right atrial shunt resulting from infective endocarditis. A unique case is described in which infective endocarditis of the aortic valve led to intractable heart failure and necropsy examination showed that the patient had developed a communication between the left ventricle and right atrium.
\end{abstract}

A communication between the left ventricle and right atrium is an uncommon condition which usually results from a congenital defect (Gerbode et al., 1958; Riemenschneider and Moss, 1967). Åberg et al. (1971) described a patient in whom this communication was found following subacute bacterial endocarditis which was probably sited on the tricuspid valve. The communication was later successfully closed surgically. We describe a patient in whom a left ventricular to right atrial shunt developed during the course of infective endocarditis of the aortic valve.

\section{CASE REPORT}

A 60-year-old man was seen as an out-patient in November 1972 complaining of fullness in the throat. He had no breathlessness nor chest pain and gave no history of rheumatic fever. A murmur had been noted when he was aged 20 . He had a slow rising pulse and a blood pressure of $190 / 100 \mathrm{mmHg}$, but the apex beat was not palpable. There was a harsh aortic systolic murmur and an early aortic diastolic murmur. The electrocardiogram showed voltage changes of left ventricular hypertrophy with normal conduction. Radiologically the heart was slightly enlarged with aortic valve calcification. The pulmonary vessels appeared normal. It was concluded that he had moderately severe aortic valve disease with stenosis and some regurgitation.

Six months later he was admitted as an emergency. For the previous nine days he had felt feverish with tightness in the chest, malaise, and frequent nose bleeds. Two weeks before the onset

${ }^{1}$ Present address: Middlesex Hospital, London W1

'Present address: Department of Anatomy, University of Bristol, Bristol 8 of these symptoms he had had some boils on the scalp. He was extremely ill with a temperature of $38.9^{\circ} \mathrm{C}\left(102^{\circ} \mathrm{F}\right)$. His pulse was 100 per minute and of small volume. The blood pressure was $120 / 75 \mathrm{mmHg}$ and the jugular venous pressure was normal. There was an ejection systolic murmur in the aortic area but no diastolic murmur was heard. At no time was the spleen palpable and he was never anaemic. The electrocardiogram showed a PR interval of 0.32 second but was otherwise unchanged from the previous recording. Blood cultures grew Staphylococcus aureus sensitive to a wide range of antibiotics including penicillin and streptomycin. He was treated with benzyl penicillin, 20 mega-units daily intravenously by constant infusion pump, and streptomycin, $1 \mathrm{~g}$ intramuscularly each day.

Although his temperature returned to normal he remained very ill and on the fifth day developed heart failure. An immediate diastolic murmur could be heard at the left sternal edge in addition to the systolic murmur. His jugular venous pressure was raised to the level of the ear lobes with prominent systolic waves. $\mathrm{He}$ had moderate peripheral oedema and crepitations at both lung bases. Splinter haemorrhages appeared and he developed atrial fibrillation. There was radiographic evidence of increasing pulmonary venous congestion and a right pleural effusion. $\mathrm{He}$ developed junctional rhythm and, despite vigorous medical treatment, remained in heart failure and died 16 days after admission.

NECROPSY FINDINGS The aortic valve was bicuspid and affected by severe calcific stenosis. Vegetations were present on the posterior cusp of the aortic 


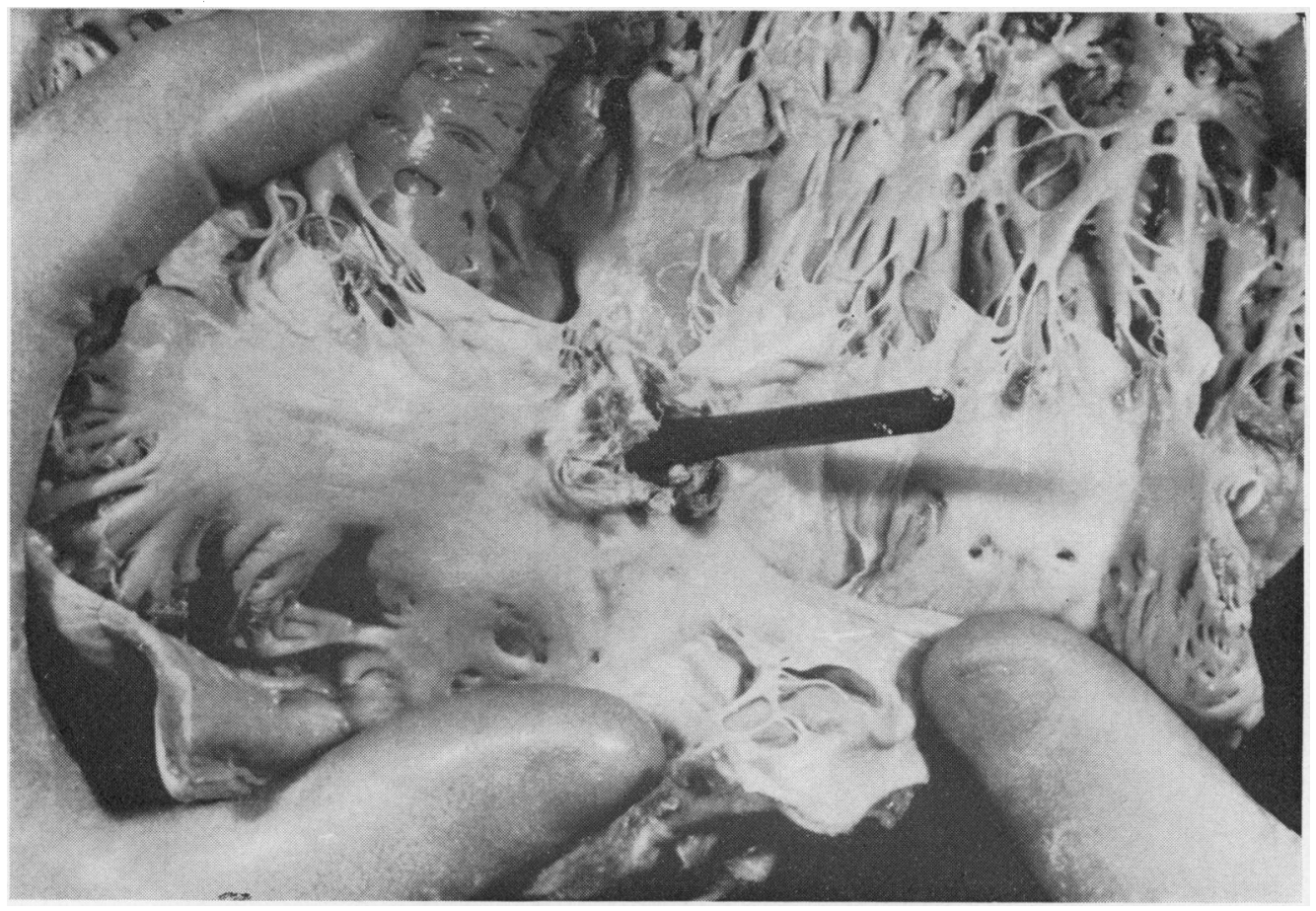

FIG. 1. The inside of the right atrium with a probe in the fistula.

valve and at the root of the tricuspid valve. In the ventricular septum was a defect, $0.5 \mathrm{~cm}$ in diameter, forming a left ventricular to right atrial communication (Figs 1 and 2). There were vegetations on a jet lesion of the tricuspid valve on the side farthest from the septal defect, and an uninfected jet lesion just below the anterior cusp of the aortic valve.

\section{DISCUSSION}

Conducting tissue disturbances appearing in active aortic valve endocarditis indicate a poor prognosis because of deep infection in the noncoronary sinus, usually with aneurysm formation (Roberts and Somerville, 1969). In our patient, electrocardiographic evidence of conduction disturbance was followed by the development of prominent systolic waves in the neck veins and

FIG. 2. A diagram of the necropsy findings: IASinteratrial septum; Ao-root of aorta; RA-right atrium; $P C$-vegetations on posterior cusp of aortic valve; $P$-perforation of membranous septum; $T V$ vegetations on base of tricuspid valve. The $A V$ bundle is the triangular shaped area deep to these; $R V$-right ventricle.

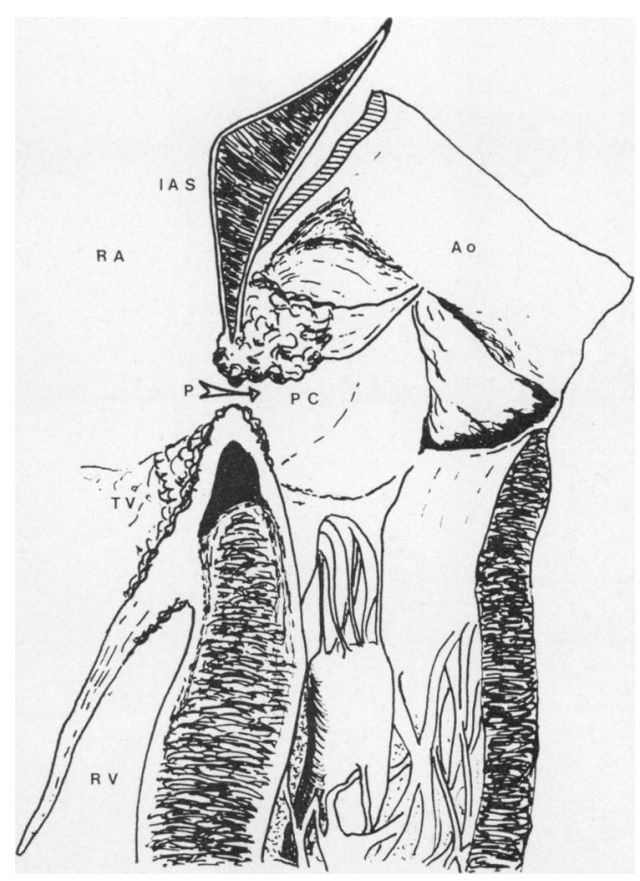


rapidly worsening congestive cardiac failure, which was largely due to the left to right intracardiac shunt.

In a review of the literature Aberg et al. (1971) found 150 examples of left ventricular to right atrial communication, of which the great majority were congenital in origin. As described above, their patient developed this lesion as the result of subacute infective endocarditis, probably sited on the tricuspid valve.

Our patient appears to be the first described in whom the original lesion was on the aortic valve.

We are grateful to Dr. J. R. Read for the report of the necropsy findings.

\section{REFERENCES}

Áberg, T., Johansson, L., Michaelsson, M., and Rhedin, B. (1971). Left ventricular-right atria shunt of septic origin. Journal of Thoracic and Cardiovascular Surgery, 61, 212.

Gerbode, F., Hultgren, H., Melrose, D., and Osborn, J. (1958). Syndrome of left ventricular-right atrial shunt. Annals of Surgery, 148, 433.

Riemenschneider, T. A. and Moss, A. J. (1967). Left ventricular-right atrial communication American Journal of Cardiology, 19, 710.

Roberts, N. K. and Somerville, Jane (1969). Pathological significance of electrocardiographic changes in aortic valve endocarditis. British Heart Journal, 31, 395.

Requests for reprints to: Dr. K. E. Gray, Bristol General Hospital, Guinea Street, Bristol BS1 6SY. 